\title{
A historiografia da arquitetura brasileira no século XIX e os conceitos de estilo e tipologia
}

SONIA GOMES PEREIRA*

Resumo: Esse artigo analisa os conceitos de estilo e tipo, examinando as suas diferenças estruturais - a base histórica e geográfica do estilo em oposição à relação entre solução formal, gênero e função no tipo -, e tentando evidenciar a operacionalidade de ambos na reavaliação crítica da produção artística do século XIX.

Abstract: The present article analyses he concepts of style and type, by examining its structural differences - the historical and geographical base of style as opposed to the relation between formal solution, genre and function concerning type - and attempts to show the operationality of both in the critical reevaluation of the artistic production of the $21^{\text {st }}$ century.

Palavras-chave: Estilo. Tipologia. Historiografia da arte. Século XIX.

Key words: Style. Typology. Historiography of art. 19st century.

Grande parte da historiografia sobre a arquitetura brasileira do século XIX apresenta a tendência dominante de trabalhar com divisões rígidas entre estilos, enfatizando a oposição entre barroco/rococó e neoclassicismo no início do século e, depois, entre neoclassicismo e ecletismo no final do século XIX/início do XX. Essa postura decorre de uma outra noção generalizada na literatura sobre arte brasileira: a idéia de que há uma correspondência "natural" entre linguagens artísticas e períodos históricos; assim o barroco predominaria na Colônia, o neoclassicismo no Império e o ecletismo na Primeira República.

Sonia Gomes Pereira é professora titular da Escola de Belas Artes da UFRJ. Fez mestrado na Universidade de Pennsylvania, doutorado na UFRJ e pós-doutorado no Laboratoire de Recherches sur le Patrimoine Français/CNRS em Paris.

Estudos Ibero-Americanos. PUCRS, v. XXXI, n. 2, p. 143-154, dezembro 2005 
Estes esquemas redutores sobrevivem nesta historiografia tradicional, apoiados numa metodologia que está fundamentada basicamente na "pinçagem" de alguns fatos históricos relevantes, tais como a chegada da Missão Francesa e a abertura da Academia de Belas Artes no Rio de Janeiro, ou de alguns arquitetos destacados, como Grandjean de Montigny, em torno dos quais toda a narrativa histórica é construída.

No entanto, suspendendo, mesmo que temporariamente, a questão das atribuições ou as preocupações meramente estilísticas, é possível observar na prática arquitetônica do século XIX um conjunto muito mais complexo, em que vários elementos estão imbricados: a persistência de formas e técnicas coloniais; a necessidade de novos programas e funções; a incorporação de materiais importados; a diversificação dos agentes; os novos processos de formação profissional de arquitetos e engenheiros; além da sincronicidade de várias linguagens formais - a recorrência aos estilos do passado (barroco e rococó) e a apreensão dos estilos então contemporâneos (o neoclassicismo e outros revivalismos, além do ecletismo e do art nouveau). Portanto, em lugar de uma só feição dominante, coexistem técnicas, programas e estilos do passado e do presente, evidenciando a permanência da tradição colonial, entrelaçada no desejo de modernização e na necessidade de construção imaginária da nova nação.

Entender essa diversidade estilística da arquitetura do século XIX, tanto na Europa quanto no Brasil, tem sido um desafio para os historiadores da arte e da arquitetura. Na verdade, essa dificuldade tem raízes profundas, relativas à própria constituição da História da Arte e a importância primordial que a noção de estilo assumiu em sua definição como disciplina autônoma.

Sabemos que etmologicamente a palavra estilo vem do latim stilus, que designava o instrumento usado para a escrita entre os romanos. Por metonímia, passou a designar também a maneira de escrever de um escritor. Toda essa discussão de estilo entre os antigos pertencia ao campo da retórica, que analisava sobretudo a escolha das palavras e sua pertinência às diferentes ocasiões, seguindo a doutrina do decorum. Essas noções da retórica espalharam-se para outros campos, como a música, a arquitetura e as artes plásticas. ${ }^{1}$ Mas é a partir do renascimento que os termos estilo,

1 Da mesma forma, a associação entre poesia e pintura - a célebre Ut pictura poesis, estabelecida por Horácio no século I - manteve-se praticamente inquestionável, até ser repelida por Lessing (1729-1781) em seu ensaio Laokon de 1766, que estabeleceu as fronteiras entre os dois campos e atribuindo às artes plásticas uma linguagem específica. 
como o mais apropriado aos progressos do espírito e do gênio, graças à temperatura amena e ditosa que reina ali durante as diferentes estações do ano". ${ }^{2}$ Winckelmann não foi o inventor dessa teoria que relaciona a cultura ao meio geográfico, ${ }^{3}$ mas essa relação tomou em seu sistema um relevo significativo. Mas, num outro tópico, Winckelmann toma uma posição nova: não considerava a arte grega em isolamento, mas, sim, no contexto da civilização grega tomada como uma totalidade. ${ }^{4}$

Portanto, ao se constituir como disciplina, a história da arte consolida uma série de noções já esboçadas anteriormente: teoria do belo ideal, estilo, evolução e analogia com o ciclo vital. A elas acrescenta algumas idéias contemporâneas, tais como a influência do clima, a concepção de povo e o interesse pela história. Essas mesmas noções são retomadas ao longo do século XIX, servindo de base a posturas bastante diferentes em relação a estilo e sua importância no estudo das artes visuais e da arquitetura.

$\mathrm{O}$ arquiteto Gottfried Semper ${ }^{5}$ acredita que todas as formas artísticas, desde as artes decorativas até a arquitetura, obedecem aos mesmos princípios, que retiram sua lógica das aplicações da técnica. Apóia a sua teoria nas idéias da biologia da época, especialmente nos princípios anatômicos de Cuvier e no evolucionismo

2 A valorização dos antigos como sendo os povos que tinham atingido o mais alto grau de perfeição na construção do belo ideal era uma unanimidade entre praticamente todos os artistas e teóricos desde o renascimento. Mas quase todos localizavam essa fase áurea da antigüidade entre os romanos, como vimos no exemplo de Vasari. No século XVIII, sobretudo entre os românticos alemães, cresce o interesse pela Grécia. Goethe (1749-1832) já compartilhava desse mesmo sentimento: chegou até as "praias da Sicília, onde, de pé, nas margens do Mediterrâneo, voltado para a Grécia, recitava os versos de Homero" (Bornheim, op. cit., p. 84).

3 A idéia da influência do clima sobre a cultura dos povos já tinha sido formulada antes. Aparece, por exemplo, em Montesquieu em L'esprit des lois de 1748. Diretamente relacionada à atividade artística, já havia aparecido em 1719 em Refléxions critiques sur la poésie et la peinture, do padre Du Bos (Bazin, Germain. História da história da arte. São Paulo: Martins Fontes, 1989, p. 111-115).

${ }^{4}$ Um século antes de Winckelmann, já aparecera uma história das artes: em 1698 Pierre Monier escrevera a Histoire des arts qui sont rapport avec le dessin idivisée en trois livres, où il est traité de son origine, de son progrès, de sa chute et de son rétablissment, incorporando vários povos: egípcios, hebreus, babilônios, gregos, romanos, decadência da arte romana, gosto gótico, idade média e renasicmento (Bazin, op. cit., p. 56). Não há, entretanto em Monier o mesmo conceito de cultura global como em Winckelmann.

5 Gottfried Semper (1803-1879) era arquiteto, teórico e historiador da arte. Exilado da Alemanha, esteve na França e na Inglaterra, onde visitou a $1^{\text {a }}$ Exposição Universal de Londres em 1551, que o impressionou muito. No ano seguinte, em 1552, publica Arquitetura e civilização. De 1855 a 1871, dirigiu a seção de arquitetura da Escola Politécnica de Zurique. Pretendia escrever uma obra bastante mais ampla, mas publicou apenas a primeira parte: os dois volumes de $O$ estilo nas artes técnicas e arquitetônicas de 1861 a 1863. 
de Darwin. 6 Para Semper, por exemplo, o estilo geométrico, encontrado nos exemplos artísticos mais antigos então conhecidos, seria devido ao uso predominante das artes têxteis na época neolítica. Assim, a origem da arte é puramente material, regulada apenas pelas questões práticas do avanço técnico.

Hippolyte Taine ${ }^{7}$ também procura articular a arte a uma explicação materialista, mas centra a sua teoria no meio físico e social. Constrói todo um sistema histórico, cujo método consiste em procurar a causalidade da criação artística nas reações do meio sobre a arte. Taine não foi o inventor dessa teoria, pois, como vimos, Winckelmann já insistia nessa idéia. Mas ele dá às influências climáticas um caráter imperativo, tentando impor à história e à arte os métodos próprios das ciências. De um lado, apóia-se na biologia. Sua teoria do meio é uma adaptação da teoria evolucionista darwiniana e do método experimental de Claude Bernard. ${ }^{8}$ Por outro lado, Taine dá um destaque ainda maior à ação dos agentes sociais sobre a produção da obra de arte, alinhando-se a idéias que vão se consolidar na escola de Durkheim e nas ciências sociais. ${ }^{9}$ Para Taine, todas as manifestações artísticas, intelectuais, morais, religiosas e institucionais de uma época guardam entre si uma certa relação: é o que ele chama lei das dependências mútuas. Estabeleceu entre estas manifestações uma relação causal, em que a arte é sempre conseqüência das outras manifestações culturais. A ação individual do artista é praticamente nula. Tanto o artista quanto a arte são produtos moldados pelo meio. As teorias de Tai-

6 Georges Cuvier (1769-1832) foi o criador da Anatomia Comparada. Criou vários princípios: a lei da subordinação dos órgãos e a lei da correlação das formas. Charles Darwin (1809-1882), após viagem à América do Sul em 1831-1836, escreveu Da origem das espécies pela via da seleção natural, publicada em 1859 - obra que teve, logo de imediato, imensa repercussão em vários campos do conhecimento.

7 Hippolyte Taine (1828-1893) foi professor de história da arte e estética na École des Beaux Artes de 1864 a 1874. Substituiu Viollet-le-Duc, que ficara nessa cátedra pouco tempo (de 1863 a 1864). O seu livro Philosophie de l'art de 1865 foi acolhido quase genericamente em ambientes acadêmicos na França.

8 Antes de se dedicar aos estudos históricos, Taine freqüentou por dois anos os cursos do Museu de História Natural. Deve decorrer daí a sua familiaridade com o método experimental de Claude Bernard (1813-1878) - célebre fisiologista, que descobriu funções do pâncreas, do fígado e do sistema nervoso, sendo o mais ilustre representante da ciência experimental do final do século XIX.

9 Émile Durkheim (1858-1917) é considerado o líder da sociologia francesa na corrente do naturalismo sociológico. Foi diretor da Sorbonnne, escreveu várias obras e foi diretor de L"année sociologique. 
ne sobre a influência do meio físico e social sobre a arte deixaram uma marca profunda e duradoura na história da arte. ${ }^{10}$

Muito diferente é a posição de Alois Riegl. ${ }^{11}$ Formado no Instituto de Pesquisas Históricas de Viena, Riegl apóia-se no método de análise histórica e comparativa, derivado da tradição filológica. A seleção de seus objetos de estudo revela a preferência por temas polêmicos e o objetivo de refutar teorias correntes em sua época. Assim, publica Stilfragen (Questões de estilo) em 1893, em que se dedica à análise do ornato vegetal, combatendo a teoria da primazia da técnica de Semper, e ao mesmo tempo inserindo-se na polêmica da época entre o Art Nouveau (Jugendstil), muito atuante em Viena, e as idéias modernistas de combate ao ornamento, como as de Adolf Loos, que serão reunidas num manifesto logo depois. ${ }^{12}$ Novamente em 1901, ao escrever As artes aplicadas na época romana tardia segundo descobertas na Áustria-Hungria, Riegl rejeita as noções de que a arte romana decorre da arte grega e que o romano tardio representa o declínio da cultura latina. Não aceita a idéia de decadência e acredita que os romanos, assim como o período romano tardio, são culturas autônomas, sem estarem necessariamente relacionadas entre si numa seqüência evolutiva. Por esses motivos, Damisch questiona a crítica posterior que considerava Riegl simplesmente um evolucionista e um determinista, acreditando que

10 Sua influência foi também grande no Brasil, devendo ser a referência teórica mais importante no final de XIX / início do XX, em autores como Duque Estrada e Araújo Viana. O contraponto a essas interpretações materialistas da arte demoraria a aparecer na crítica das artes visuais no Brasil. A influência dos teóricos da chamada Escola de Viena só despontam nos anos 1940, sobretudo através do interesse na valorização do barroco entre os pesquisadores do SPHAN. Este deve ser um dos motivos da acolhida à Hanna Levy e o espaço que foi aberto a ela nas publicações dessa instituição.

11 Alois Riegl (1858-1905) foi formado no Instituto de Pesquisas Históricas de Viena, que mantinha estreita ligação com a filologia e a Escola Francesa de Chartres. Dirigiu o Departamente de Artes Têxteis do Museu de Artes Decorativas durante 12 anos (de 1885 a 1897). Assumiu a cátedra de história da arte na Universidade de Viena em 1897. Publicou várias obras. Em 1893, Stilfragen (Questões de estilo). Em 1901, As artes aplicadas na época romana tardia segundo as descobertas na Áustria-Hungria. Em 1902, O retrato de grupo na Holanda do século XVII. Deixou manuscrita a Gramática Histórica das artes plásticas, escrito em 1897-1898, e publicada por Swoboda e Otto Pächt em 1963.

12 Em Stilfragen, combate a tese de primazia da técnica exatamente em cima das artes têxteis, que tinham, como foi visto antes, uma importância fundadora na teoria de Semper. As críticas ao ornamento feitas pelo modernismo têm em Adolf Loos o seu verdadeiro manifesto: Ornament und Verbrechen (Ornamento e crime), redigido em 1908 e publicado em 1912 na revista Der Sturm. 
Riegl cita Darwin justamente para manter distância, pois rejeita totalmente a noção de seleção natural. ${ }^{13}$

Mas, certamente, a teoria de Riegl está centrada na idéia de continuidade, e não na de ruptura. Para ele, há uma criatividade contínua, identificada por uma série de transformações, menos pelo desejo de imitar a natureza, e muito mais pelas possibilidades virtuais das formas, que constituem as leis do estilo. Para Riegl, não há imperativo técnico, mas sim uma Kuntswollen, que Otto Pächt traduz por "aquilo que determina a arte": muito mais do que vontade, como é normalmente traduzido, trata-se de uma pulsão, como no conceito freudiano. ${ }^{14}$

Outros teóricos poderiam ser aqui mencionados, mas esses três autores - Semper, Taine e Riegl - já nos bastam para evidenciar a diversidade de abordagens, em que a noção de estilo é tomada no século XIX.

É bastante significativo que o problema do estilo e suas implicações para a história e crítica da arte sejam retomados nos anos 1950 e 1960, justamente quando se avolumam as críticas ao modernismo e começa a se constituir o pós-modernismo.

Meyer Schapiro escreve em 1955 o artigo Style que se tornou clássico na área. ${ }^{15}$ Nele, Schapiro enumera as várias dimensões e conotações da palavra estilo, finalizando por reafirmar aquela que constitui, na sua opinião, a abordagem mais importante: muito mais do que o material, ou o meio, é a análise da forma como expressão que distingue a obra de arte. O conceito é colocado em termos individuais ou no máximo em termos de escolas artísticas, mas não estende a noção para nenhum idéia de cultura global. Relaciona essa abordagem diretamente com a teoria de arte moderna, o que parece coerente numa década em que o informalismo se revigora, tanto na Europa quanto nos Estados Unidos.

13 Damisch, Hubert. "Le texte mis à nu". In: Riegl, Alois. Les questions de style. Paris: Hazan, 1992. Prefácio p. IX-XXI. Damisch acredita que Riegl esteja mais próximo de Lamarck (1744-1820), que apresentou a teoria da vontade animal, que foi também examinada por Freud.

14 Assim como Alberti, Riegl enfatiza o ornato como arte de superfície. A passagem das artes plásticas para as artes de superfície sempre implica numa maneira de projeção, na acepção geométrica do termo: representação gráfica de linhas. Essas linhas não existem na natureza, com exceção dos vegetais, como nas folhas, por exemplo. Mais do que a invenção do contorno, do traço e da impressão, é o ato de traçar que importa em todo o desenho: indício de uma pulsão artística. Essa dimensão pulsional está naturalmente sempre sujeita a limitaçòes e à observâncisa de regras e princípios, que caracterizam o estilo.

15 Meyer Schapiro (1994-1995) foi professor da Columbia University em Nova York. Esse artigo foi publicado pela primeira vez em Kroeber, Alfred, ed. Anthropology today. Chicago: University of Chicago Press, 1953. 
Ernst Gombrich publica um artigo também chamado Style em 1968. ${ }^{16}$ Sua posição é de intenso questionamento das teorias do estilo, tanto as materialistas quanto as idealistas. Na verdade, o seu argumento está centrado no caráter holístico dessas teorias, que implicam sempre num a priori, que dá sentido à arte e à cultura como um todo, submetidas, assim, a um determinismo inexorável. ${ }^{17}$ Não aceita as tentativas de determinar a lógica interna de uma evolução, tomando-a como inevitável e genérica, pois, para ele, os estilos traçados numa evolução são sempre recortes arbitrários Recusa também as tentativas de caracterizações sincrônicas, que vêem o estilo como expressão do espírito coletivo, criticando o Kunstwollen ("vontade" da arte), o Zeistgeist (espírito de época) e o Volksgeist (espírito do povo). Identifica em Hegel a origem desta idéia e acredita que "toda a historiografia do XIX e parte do XX tentou se livrar dos traços embaraçosos da metafísica de Hegel, sem sacrificar sua visão unitária". Assim, todas essas teorias, que têm um caráter $a$ priori, fundam-se sobre uma presumida interdependência entre estilo e sociedade, constituindo, na sua opinião, generalizações questionáveis. Para Gombrich o futuro está sempre aberto e o artista está sempre compelido a fazer escolhas. A questão central de toda a teoria da expressividade é, portanto, o conceito de escolha, estando a sinonímia na raiz de todo o problema de estilo. Logicamente essas escolhas não são ilimitadas: há restrições impostas pelas diversas situações pessoais ou do meio, mas o artista tem sempre um grau de latitude para escolhas. Na opinião de Gombrich, são exatamente essas limitações e escolhas que devem ser observadas. A maneira de identificar os estilos decorre em parte da familiaridade com as suas convenções e o preenchimento ou não dessas expectativas. Apesar dos esforços de uma morfologia científica, que pretende dar conta da constituição dos estilos, a tomada intuitiva do especialista ainda é o melhor caminho, embora não infalível.

A superação do modernismo e a confrontação com a arte e a crítica pós-modernas têm obrigado os historiadores da arte a revisões profundas em seus embasamentos teóricos e metodologias. Superar a pretensão de que seria possível reconstituir o passado totalmente e com a máxima verdade possível. Compreender a sin-

16 Ernst Gombrich foi professor do Warburg Institute em Londres e seu diretor de 1959 a 1976. Foi também professor nas Universidades de Oxford e Cambridge. Esse artigo Style foi publicado na International Encyclopaedia of the Social Sciences. New York: Marmillan, 1968, tomo 15.

17 Gombrich foi muito influenciado por K. R. Popper, especialmente pela sua obra Pobreza do Historicismo de 1957, em que critica e refuta o holismo cultural. 
cronicidade de processos de longa, média e curta duração, em lugar da sucessão e superação dos estilos. Entender também a sincronicidade de tendências estéticas opostas (clássicas e anticlássicas, por exemplo), em lugar da sua ocorrência cíclica. Todos esses passos têm sido um desafio para o historiador da arte nesta passagem do século XX para o século XXI. Outras categorias passam a ter importância ao lado do estilo na tentativa de entender a produção artística em sua complexidade.

Muito se avançou nas pesquisas sobre a arquitetura do século XIX a partir de alguns trabalhos de reavaliação crítica do ecletismo, como os de François Loyer e de Luciano Patetta. ${ }^{18}$ Suspendendo o ponto de vista modernista, esses estudos retomavam o ecletismo como um sistema diferenciado de valores e práticas, em que se destacava, entre outros, a função do ornamento como elemento que daria caráter à arquitetura. Seria uma verdadeira architecture parlante, em que sobretudo o ornamento teria um valor associativo, conotando certas linguagens a determinadas funções. Assim, um dos traços recorrentes da arquitetura historicista é a associação entre determinados programas e estilos, tais como os prédios religiosos e os estilos medievais; ou os monumentos públicos e o neoclássico ou o neo-renascimento; ou os pavilhões voltados para o lazer e os estilos exóticos. Seria uma verdadeira tipologia definida pela relação entre estilo e função.

Mas a tipologia era também um recurso historiográfico. A partir do século XVIII, tornaram-se bastante comuns os levantamentos de monumentos históricos, agrupando-os por tipologias, que tanto podiam ser ditadas pela função comum, quanto pela recorrência a um mesmo padrão formal. Certamente esse procedimento era sugerido pelos novos métodos científicos da época, em que a exposição conjunta dos espécimes era fundamental para a identificação de semelhanças e diferenças levando à sua classificação.

18 Loyer, François. “Ornement et caracterère”. In: Le siècle de l'eclectisme: Lille 1830-1930. Paris/Bruxelles: Archives d'architecture moderne, 1977; Patetta, Luciano. "Considerações sobre o ecletismo na Europa". In: Fabris, Annateresa, org. Ecletismo na arquitetura brasileira. São Paulo: Nobel / Edusp, 1987. 


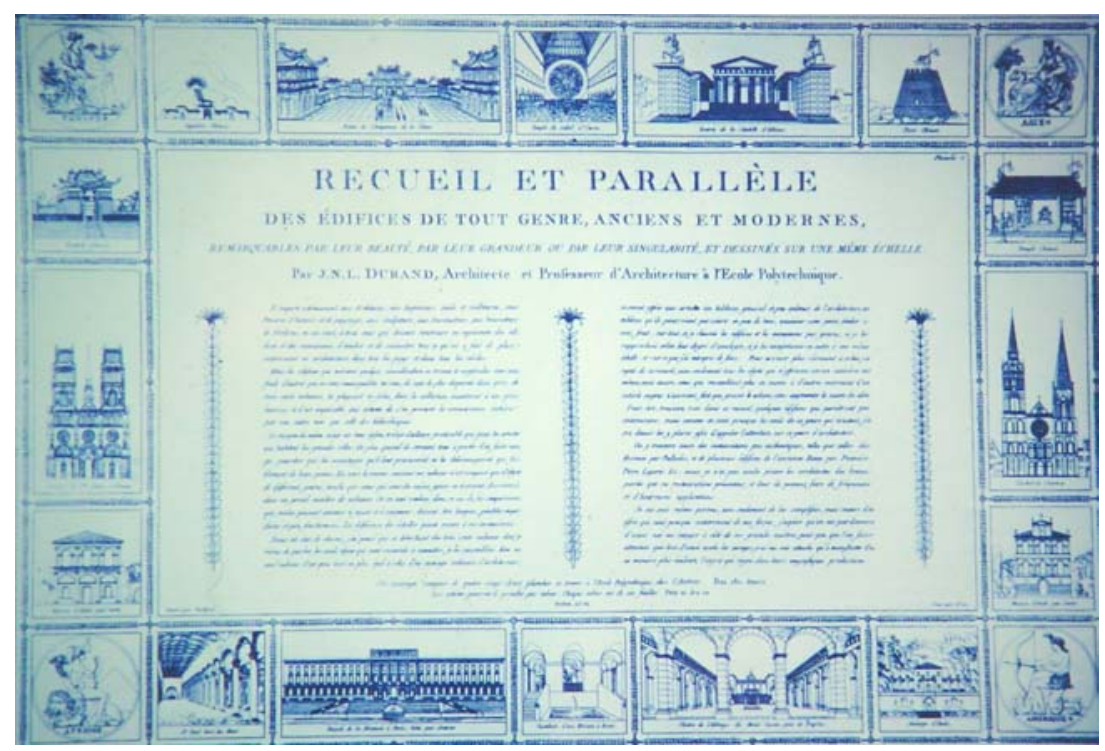

Capa do livro Récueil et parallèle des édifices de tout genre, anciens et modernes, remarquables par leur grandeur ou par leur singularité, et dessinés sur une même échelle, de Jean-Nicholas-Louis Durand (1760-1834), publicado em Paris em 1799-1801. As vinhetas nos ângulos representam os quatro continentes. Há vários monumentos da Ásia (China), um da América (Templo do sol em Cuzco) e vários da Europa (reunindo obras clássicas antigas e do renascimento, e também medievais).

É nessa direção que se pode analisar o uso que Durand ${ }^{19} \mathrm{fez}$ da tipologia. Ele não aceitava mais a idéia da arquitetura como imitação da natureza ou dos antigos; ao contrário, acreditava que as ordens e demais formas históricas eram importantes pela força do hábito e do costume. Assim, sua tipologia apoiava-se no levantamento histórico e concretizava-se em catálogos de prédios com funções ou partidos similares, em que ficavam evidenciados os padrões comuns. Para Durand, o tipo era uma composição

19 Durand, Jean-Nicholas-Louis (1760-1834) era arquiteto formado pela Academia Real de Arquitetura de Paris. Foi professor de arquitetura na Escola Poletécnica a partir de 1796. Escreveu duas obras que se tornaram manuais obrigatórios para os estudantes de arquitetura e engenharia em todo o século XIX: Recueil et parallèle des édifices en tout genre, anciens et modernes, remarquables par leur beauté, par leur grandeur ou par leur singularité, et dessinés sur une même échelle. Paris, 1799-1801. Durand, JeanNicholas-Louis. Précis des leçons d'architecture données à l'École Polytechnique., Paris: $1802-1805.2 \mathrm{v}$. 
característica de projeto, que, apesar de não ter mais a autoridade de um cânone, concentrava a força de uma tradição histórica.

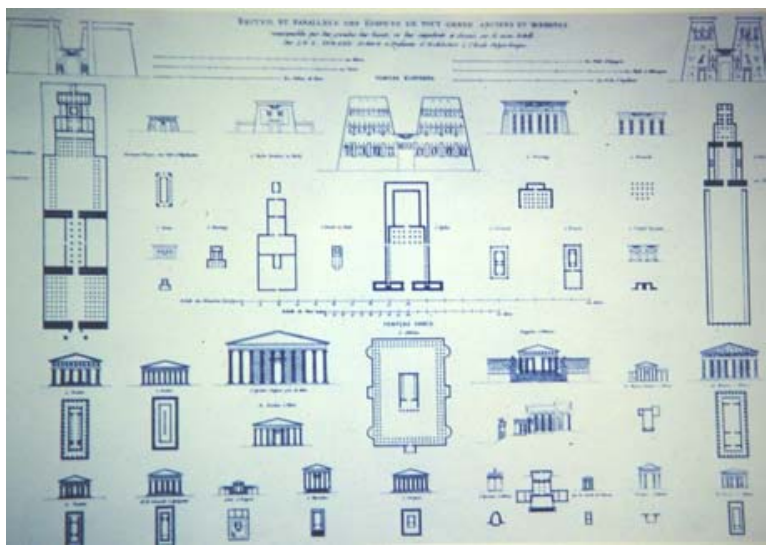

Durand, Récueil et parallèle, prancha Temples égyptiens et grecs. Aqui, encontram-se reunidas séries do tipo templo, com obras da Antigüidade no Egito e na Grécia. Assim, essa tipologia tem caráter funcional e está submetida ao critério histórico e geográfico.

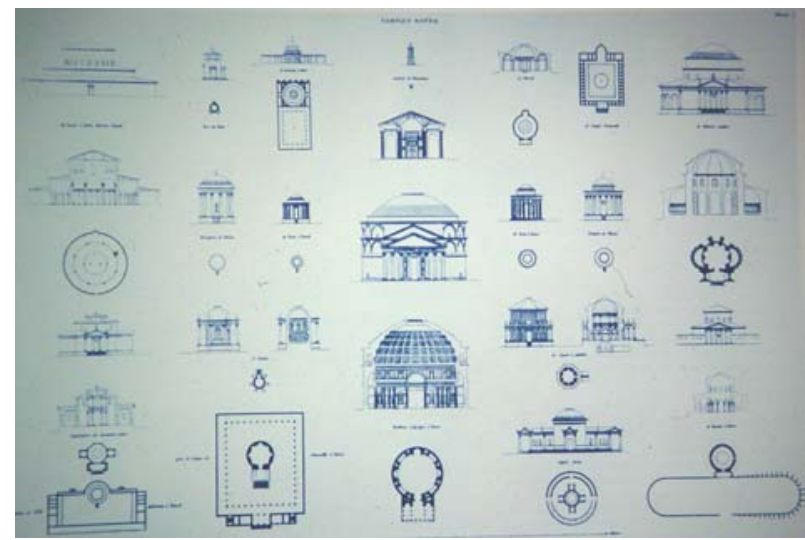

Durand, Récueil et parallèle, prancha Temples Ronds. Já essa série foi formada por templos de várias épocas e lugares (Grécia e Roma antigas, renascimento italiano) em torno de um tipo de solução espacial (templo redondo). Trata-se, portanto, de uma tipologia fundamentada na função e no partido e acima da história e da geografia.

É importante assinalar que essas pranchas, apesar de decorrentes de um conhecimento histórico, acabavam gerando uma tipologia acima da história e da geografia, exatamente o contrário da noção de estilo. Pois, se o estilo era determinado temporal e 
espacialmente, tal não acontecia com o tipo, que se ancorava em características comuns, em termos de função ou partido. Diante dessas pranchas, é como se o arquiteto tivesse exposto diante de si toda uma tradição arquitetônica à sua disposição para ser reutilizada nos prédios contemporâneos. Mais do que imitar simplesmente o passado, trata-se de aproveitar de sua notável experiência. A sua exemplaridade avaliza as escolhas do arquiteto e garante a legitimidade de sua arquitetura. Temos aqui, também, todo um processo de escolha entre alternativas possíveis, como aquela que Gombrich indica como sendo específica do trabalho artístico.

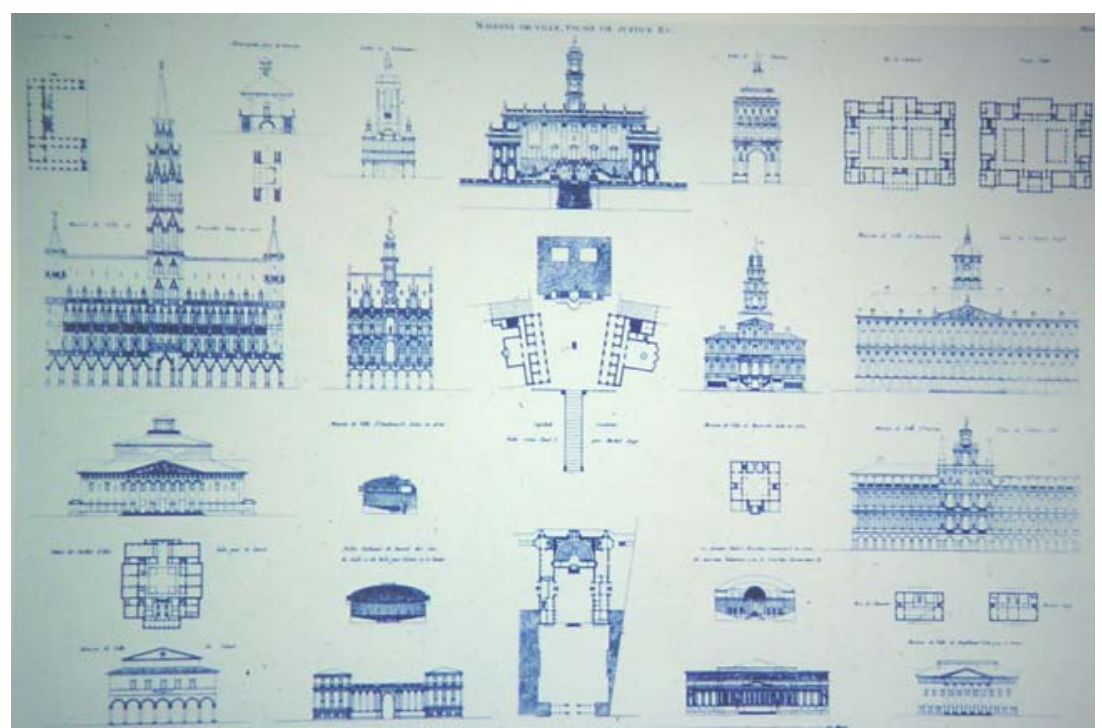

Durand, Récueil et parallèle, prancha Maisons-de-ville, Palais de Justice. Para esse tipo, a série incorpora exemplos medievais, que certamente tinham valor simbólico na tradição das cidades européias. Aqui, o critério foi funcional e também acima da história e da geografia. tTT.

Ao contrário de Durand, Quatremère de Quincy 20 aceitava a validade da tradição clássica, acreditando na permanência de uma essência na arquitetura, que estaria localizada em suas origens. A diferença é que essa origem não estaria apenas na cabana primitiva, como se afirmava antes, mas em três elementos - a gruta usada pelos caçadores, a tenda dos pastores e a cabana dos campo-

20 Quatremère de Quincy (1755-1849) foi secretário da classe das Belas Artes, depois Academia de Belas Ares de 18161 1839. O verbete Type foi publicado originalmente na Encyclopédie méthodique: Architecture. Paris: Panckoucke, 1788-1825. 
neses - tendo esses elementos sido desenvolvidos por diferentes povos: a gruta pelos egípcios, a tenda pelos chineses e a cabana pelos gregos. Fica, assim evidenciado que Quatremère, apesar de ainda atrelado ao pensamento clássico, já incorporara uma visão histórica e relativista. Também em relação à imitação, é possível verificar essa historicização do classicismo. Quatremère estabeleceu uma diferença entre modelo, que é uma coisa, e tipo, que é uma idéia e que constituiu a única base válida para imitação. A essência do tipo é um princípio elementar, espécie de núcleo, mas apresenta-se diferente em cada país. ${ }^{21}$ Retomada por Argan nos anos 1960, a noção de tipologia tornou-se tema central do discurso arquitetônico. Argan adotou a distinção entre tipo e modelo de Quatremère, enfatizando que apenas o tipo deveria ser o ponto de partida para o projeto. Passando para o campo do urbanismo e da preservação do patrimônio, Aldo Rossi propunha o tipo como contendo idéias, que são os elementos irredutíveis nas cidades elementos culturais que deveriam ser preservados. Posteriormente, apesar da diferença de contexto, essas idéias obtiveram bastante aceitação entre os arquitetos nos Estados Unidos. ${ }^{22}$

Acreditamos, portanto, que esta relação tipo/estilo lança uma luz nova no entendimento das opções formais dessa arquitetura, evidenciando que, muito mais do que escolhas estilísticas, tratamse em grande parte de escolhas tipológicas, que devem ter sido de grande operacionalidade nos embates entre tradição e modernidade na Europa e, no caso brasileiro, nos projetos de modernização e de construção da nação no século XIX.

21 Carol W. Westfall afirma que, durante a tradição clássica, tipo é uma terminologia imprecisa, mas de qualquer maneira circunscrita ao campo da arquitetura. Mais ou menos em 1800, há uma ruptura. Nova epistemologia relativista e historicista vai proceder à classificação dos prédios segundo categorias de estilo e caráter. No entanto, duas noções de tipo sobreviveram, formuladas mais ou menos em 1800: a de Durand e a de Quatremère. São noções diferentes, mas ambas alternativas à tentativa relativista e historicista dominante de reduzir o conhecimento da arquitetura à história dos estilos arquitetônicos. As noções mais antigas de tipo não sobreviveram: o termo passou a ser usado para referir alguma coisa fora do corpo tradicional da arquitetrua. (Westfall, Carol S. \& Van Pelt, Robert J. Architectural principles in the age of historicism. New Haven and London: Yale University Press, 1993, p. 145-148).

22 Argan, Giulio Carlo. El concepto del espacio arquitectónico - desde el barroco a nuestros dias. Buenos Aires: Ediciones Nueva Visión, 1973. p. 29-36. Rossi, Aldo. The architecture of the city. Cambridge: MIT Press, 1942. p. 41. 